\title{
INVESTIGAÇÃO IN VITRO DA ATIVIDADE ANTICOLINESTERÁSICA DE FRAÇÕES DE Ocotea glaziovii
}

\author{
Janaína da Silva Ribeiro'; Mariana Borges Botura²; Raquel Bianca Marchesine de \\ Almeida $^{3}$ e Rodrigo Souza Conceição ${ }^{4}$ \\ 1. Bolsista FAPESB, Graduanda em Farmácia, Universidade Estadual de Feira de Santana, e-mail: janaafsa@gmail.com \\ 2. Orientadora, Departamento de Saúde, Universidade Estadual de Feira de Santana, e-mail: mbbotura@uefs.br \\ 3. Doutoranda do Programa de Pós-Graduação em Biotecnologia, Departamento de Ciências Biológicas, Universidade \\ Estadual de Feira de Santana, e-mail: raquelbma87@gmail.com \\ 4. Doutorando do Programa de Pós-Graduação em Biotecnologia, Departamento de Ciências Biológicas, Universidade \\ Estadual de Feira de Santana, e-mail: rodrigoszc@gmail.com
}

PALAVRAS-CHAVE: Ocotea, acetilcolinesterase, butirilcolinesterase

\section{INTRODUÇÃO}

Os fármacos com ação anticolinesterásica têm sido utilizados no tratamento de doenças neurodegenerativas associadas à déficits de acetilcolina, principalmente da doença de Alzheimer. A maioria dos medicamentos disponíveis possuem afinidade apenas para a acetilcolinesterase (AChE), porém substâncias com capacidade de atuar sobre as duas colinesterases podem potencializar e prolongar o benefício do tratamento anticolinesterásico (Freitas et al., 2009).

O gênero Ocotea representa um dos principais membros da família Lauraceae. No Brasil, este gênero é representado por cerca de 170 espécies distribuídas em várias regiões do Brasil, inclusive no Nordeste (Brotto e Baitello, 2012). Dentre as atividades biológicas relatadas para algumas espécies de Ocotea, pode-se destacar o efeito carrapaticida (Conceição et al., 2017) e anticolinesterásico (Amoo et al., 2012).

Uma importante espécie do gênero Ocotea, é a Ocotea glaziovii (Mez), que possui como principal metabólito secundário um alcaloide proaporfínico, conhecido como glaziovina. Este alcaloide foi isolado pela primeira vez por Gilbert e cols. (1965) a partir da O. glaziovii. A esta substância foram atribuídas propriedades ansiolítica e tranquilizante, sendo registrada com o nome comercial de Suavedol ${ }^{\circledR}$ nos anos 70 como uma especialidade terapêutica do laboratório SIMES (Peréz et al., 2005). Estudos prévios realizados por nosso grupo de pesquisa revelaram potencial atividade in vitro de diferentes extratos de $O$. glaziovii frente as colinesterases. O presente trabalho teve como objetivos avaliar in vitro o efeito inibitório de frações obtidas do extrato etanólico de Ocotea glaziovii frente as enzimas acetilcolinesterase (AChE) e butirilcolinesterase (BuChE).

\section{METODOLOGIA}

Coleta e identificação botânica: Folhas de $O$. glaziovii (aproximadamente $2 \mathrm{Kg}$ ) foram coletadas na região de Morro do Chapéu e identificadas no Herbário da Universidade Estadual de Feira de Santana (HUEFS), onde foi depositada a exsicata de número 205863.

Obtenção do extrato etanólico: $O$ material vegetal foi seco em estufa com temperatura controlada $\left(40^{\circ} \mathrm{C}\right)$ e moído em moinho de facas (tipo Wiley). O material moído foi submetido à maceração com etanol e posteriormente filtrado. $\mathrm{O}$ extrato etanólico foi fracionado por partição líquido-líquido com hexano e acetato de etila. Após este procedimento, os respectivos solventes foram evaporados utilizando rotoevaporador rotativo.

Fracionamento do extrato etanólico de Ocotea glaziovii: O extrato etanólico de $O$. glaziovii (20 g) foi submetido ao fracionamento por cromatografia em coluna (CC) utilizandose sílica gel 60 (70-230 mesh, VETEC) como fase estacionária. O material foi eluído com os solventes hexano e acetato de etila em ordem crescente de polaridade para obtenção das frações, conforme apresentado na Tabela 1. 
Tabela 1: Solventes utilizados no fracionamento do extrato etanólico de Ocotea glaziovii por cromatografia em coluna aberta e frações obtidas

\begin{tabular}{|c|c|}
\hline Solvente & Fração \\
\hline Hexano $(100 \%)$ & Fração $1,2,3,4,5,6$ e 7 \\
\hline Hexano - acetato de etila (90: $10 \%)$ & Fração $8,9,10,11,12,13,14$ e 15 \\
\hline Hexano - acetato de etila (80:20\%) & Fração 16 e 17 \\
\hline Hexano - acetato de etila (70:30\%) & Fração 18, 19, 20, 21, 23, 24 \\
\hline Hexano - acetato de etila (60: $40 \%)$ & Fração 25 e 26 \\
\hline Hexano - acetato de etila (50: $50 \%)$ & Fração 27,28 e 29 \\
\hline Hexano - acetato de etila (40: $60 \%)$ & Fração 30,31 e 32 \\
\hline Hexano - acetato de etila (30: $70 \%)$ & Fração 33 \\
\hline Hexano - acetato de etila (20: $80 \%)$ & Fração 34 e 35 \\
\hline Hexano - acetato de etila (10: $90 \%)$ & Fração 36,37 e 38 \\
\hline Hexano - acetato de etila (3: $97 \%)$ & Fração 40, 41, 42 e 43,44 e 45 \\
\hline Acetato de etila (100\%) & Fração $46,47,48,49,50,51$ e 52 \\
\hline
\end{tabular}

As frações obtidas foram analisadas por cromatografia em camada delgada (CCD) utilizando como eluente os seguintes sistemas de solvente: acetato de etila/hexano (5:5), acetato de etila/hexano (7:3), acetato de etila/hexano (8:2). Foram utilizadas cromatofolhas de alumínio (Merck), que permitem a visualização em UV (254 nm). As frações 1 e 2; 3, 4, 5, 6, 7 e $8 ; 9,10$ e 11; 12, 13 e 14; 15 foram unidas por apresentarem perfil similar nesta análise, resultando em cinco frações.

Avaliação in vitro da inibição da atividade anticolinesterásica: $\mathrm{O}$ efeito das frações de $O$. glaziovii sobre a atividade das enzimas acetilcolinesterase e butirilcolinesterase foi avaliado de acordo com o método de Ellman (1961) e modificado por Tan et al. (2014). Nos poços de microplacas (96 poços) foram adicionados $140 \mu \mathrm{L}$ de solução tampão fosfato contendo albumina sérica bovina $(0,1 \%), 20 \mu \mathrm{L}$ das frações em diferentes concentrações (diluídos em etanol a 10\%), $20 \mu \mathrm{L}$ das enzimas (acetilcolinesterase e butirilcolinesterase 0,15 $\mathrm{U} / \mathrm{mL}$ ), e a placa foi incubada a temperatura ambiente durante 30 minutos. Após esse período, foram adicionados $10 \mu \mathrm{L}$ de solução de iodeto de acetilcolina $(75 \mathrm{nM}), 10 \mu \mathrm{L}$ de solução de iodeto de butiriltiocolina $(14 \mathrm{mM})$ e $10 \mu \mathrm{L}$ de DTNB $(10 \mathrm{mM})$. A eserina $(50 \mu \mathrm{M})$ foi utilizada como controle positivo e os controles negativos consistiram na solução tampão fosfato $0,1 \mathrm{M}$ e etanol (1\%). A absorbância foi medida a $405 \mathrm{~nm}$ em leitor de microplaca nos tempos de 0 e 30 minutos. A porcentagem de inibição da colinesterase foi calculada através da comparação das velocidades de reação (hidrólise do substrato) das amostras em relação ao controle negativo.

Análise Estatística: Os resultados foram avaliados pela ANOVA seguido do teste de Tukey ( $\mathrm{p}<0,001$ ), utilizando o programa estatístico Graphprism (versão 5.0).

\section{RESULTADOS E DISCUSSÃO}

$\mathrm{Na}$ avaliação in vitro do efeito inibitório das frações obtidas do extrato etanólico de $O$. glaziovii sobre a atividade da acetilcolinesterase (AChE), foi observado, na concentração testada $(2 \mathrm{mg} / \mathrm{mL})$, os seguintes percentuais de inibição: 44,26; 38,34; 6,00;23,09 e 34,36\% para as frações 1, 2, 3, 4 e 5, respectivamente (Figura 1). Todos os tratamentos diferiram estatisticamente do controle negativo (etanol $2 \%)(\mathrm{p}<0,001)$. 


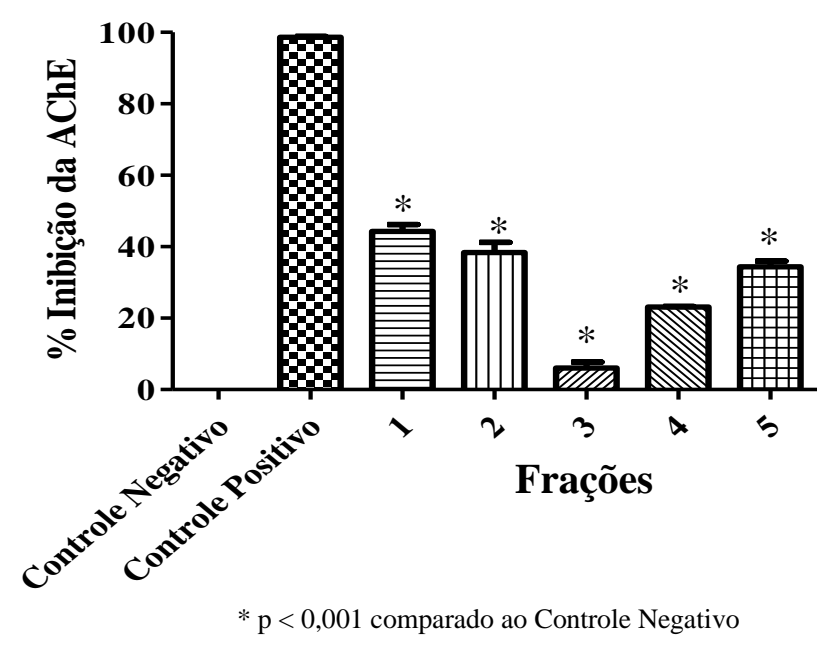

Figura 1: Média e desvio padrão do percentual de inibição da atividade da acetilcolinesterase após exposição as frações de Ocotea glaziovii

As frações de $O$. glaziovii exibiram maior efeito inibitório in vitro sobre a atividade da BuChE, com exceção da fração 3. Os percentuais de inibição corresponderam a 81,18; 34,59; 5,67; 52,85 e 55,07\% para as frações 1, 2, 3, 4 e 5, respectivamente (Figura 2). Todos os tratamentos diferiram estatisticamente do controle negativo (etanol $2 \%)(\mathrm{p}<0,001)$.

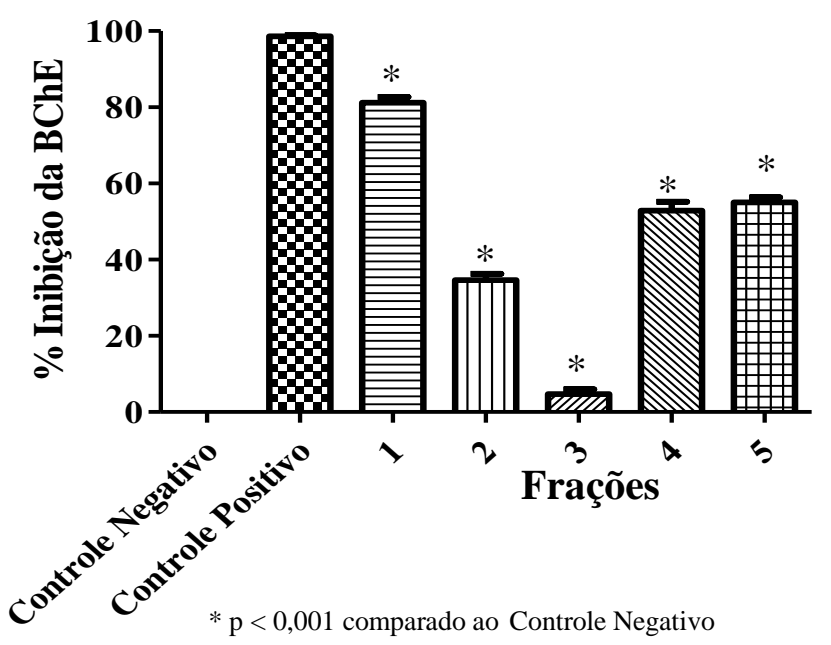

Figura 2: Média e desvio padrão do percentual de inibição da atividade da butirilcolinesterase após exposição as frações de Ocotea glaziovii

De acordo com Vinutha et al. (2007), a atividade anticolinesterásica de um extrato pode ser considerada como potente quando o percentual de inibição da atividade enzimática for maior ou igual a 50\%, moderada quando estiver entre 30 e $50 \%$ e fraca quando for menor que $30 \%$. No presente estudo, os tratamentos com a fração 1 e fração 5 de O. glaziovii resultaram em inibição da BuChE superior a $50 \%$ (Figura 2), enquanto que a inibição da $\mathrm{AChE}$ foi inferior a $50 \%$ para todas as frações (Figura 1). Maior sensibilidade da enzima $\mathrm{BuChE}$ aos efeitos das frações podem estar relacionadas com as diferenças estruturais entre as colinesterases.

A atividade anticolinesterásica dos extratos de Ocotea glaziovii foi avaliada por Lima (2016) e o extrato etanólico, utilizado para obtenção das frações deste estudo, foi o mais ativo com efeito inibitório igual a 99,3\% e $87,7 \%$ frente a AChE e BuChE, respectivamente. 
Considerando estes dados, observa-se que as frações apresentaram menor atividade em relação ao extrato do qual foram obtidas. Esse resultado sugere uma possível ação sinérgica de diferentes compostos nesta atividade biológica.

Dentre os possíveis compostos bioativos presentes na espécie O. glaziovii é a glaziovina (alcaloide proaporfínico), que tem sido relacionado com diferentes atividades biológicas desta planta, incluindo ansiolítica e antiulcerosa (Pérez et al., 2005). Estudo anterior realizado por Yamaguchi, Alcântara e Veiga Júnior (2012) também identificou atividade anticolinesterásica de extratos etanólicos de folhas e galhos em diferentes espécies de Ocotea, como O. minor, O. leucoxylon e O. ceanothifolia. Estes autores correlacionaram o efeito anticolinesterásico com a presença de alcaloides nas espécies de Ocotea.

\section{CONSIDERAÇÕES FINAIS}

A partir dos resultados obtidos neste estudo pode-se concluir que a espécie $O$. glaziovii possui pronunciado efeito inibitório in vitro frente a enzima butirilcolinesterase, sendo a fração 1 a mais ativa.

Este trabalho identificou importante atividade biológica em espécie de Ocotea, o que poderá contribuir para o desenvolvimento de novos fármacos inibidores das colinesterases. No entanto, torna-se necessário a realização de novos estudos farmacológicos, toxicológicos e isolamento das substâncias bioativas para melhor caracterização de seus potenciais efeitos terapêuticos.

\section{REFERÊNCIAS}

AMOO, S.O. 2012. Antioxidant and acetylcholinesterase-inhibitory properties of long-term stored medicinal plants. BMC Complementary and Alternative Medicine 12(1): 1-9.

BROTTO, M.L.; BAITELLO, J.B. 2012. Uma espécie nova de Lauraceae da floresta atlântica do Brasil. Rodriguésia 63(3): 579-585.

CONCEIÇÃO, R.S. 2017. In vitro acaricide activity of Ocotea aciphylla (Nees) Mez. (Lauraceae) extracts and identification of the compounds from the active fractions. Ticks and Tick-borne Diseases 8: 275-282.

ELLMAN, G.L. 1961. A new and rapid colorimetric determination of acetylcholinesterase activity. Biochem. Pharmacol. (7): 88-95.

FREITAS, H.F.; PAZ, O.S.; CASTILHO, M.S. 2009. Estudos de QSAR 3D para um conjunto de inibidores de butirilcolinesterase humana. Química Nova 32(8): 13-22.

GILBERT, B.; GILBERT, M.E.A.; RIBEIRO, O.; HOLLSTEIN, U.; WICKBERG, B.; WENKERT, E.; OLIVEIRA, M.M.; RAPOPORT, H. 1965. Journal of the American Chemical Society 86(1): 694.

LIMA, F.A. 2016. Determinação in vitro da atividade anticolinesterásica de extratos de Ocotea glaziovii. Universidade Estadual de Feira de Santana, Monografia.

PÉREZ, E.G.; SÁEZ, J.; CASSELS, B.K. 2005. A convenient, renewable source of the anxiolytic proaporphine alkaloid glaziovine: Duguetia vallicola leaves. Journal of the Chilean Chemicam Society 50(3): 553-557.

TAN, W.N.; KHAIRUDDEAN, M.; WONG, K.C.; KHAW, K.Y.; VIKNESWARAN, M. 2014. New cholinesterase inhibitors from Garcinia atroviridis. Fitoterapia 97: 261-267.

VINUTHA, B.; PRASHANTH, D.; SALMA, K.; SREEJA, S.L.; PRATITI, D.; PADMAJA, R.; RADHIKA, S.; AMITA, A.; VENKATESHWARLU, K.; DEEPAK, M. 2007. Screening of selected Indian medicinal plants for acetylcholinesterase inhibitory activity. Journal of Ethnopharmacology 109(3) 65-71.

YAMAGUCHI, K.K.L.; ALCÂNTARA, J.M.; VEIGA JÙNIOR, V.F. 2012. Investigação do potencial antioxidante e anticolinesterásico de 20 espécies da família Lauraceae. Acta Amazonica. 42(2): 541-546. 